\title{
Effect of Oxidation Treatment on Microstructure and Electrochemical Properties of 6061 Aluminum Alloy
}

\author{
Zhisheng Wang, Yanhua Lei, KunChen, QingHong Li, Yansheng Yin, Runhua Fan \\ College of Ocean Science and Engineering, Shanghai Maritime University, 1550 Hai gang Avenue, \\ Shang hai201306, China \\ *E-mail: rhfan@shmtu.edu.cn
}

doi: $10.20964 / 2021.02 .08$

Received: 29 September 2020 / Accepted: 12 November 2020 / Published: 31 December 2020

\begin{abstract}
In this paper, $6061 \mathrm{Al}$ alloy was used as the matrix to prepare the anodic film by acidification. SEM, XRD and EDS were used to study the effect of oxidation treatment on the structure and corrosion resistance of $6061 \mathrm{Al}$ alloy. The results show that the grain size of $6061 \mathrm{Al}$ alloy is larger, and the second phase particles are distributed in the grain. After oxidation treatment, fine second phase particles were precipitated in the grains, resulting in the increase of the strength of $6061 \mathrm{Al}$ alloy. The tensile and impact fracture of $6061 \mathrm{Al}$ alloy treated by oxidation shows the characteristics of intergranular fracture. Surface anodic oxidation treatment can significantly reduce the mechanical property loss of $6061 \mathrm{Al}$ alloy. Compared with bare materials, the initiation and expansion of intercrystalline corrosion can be effectively inhibited, and the strength and plasticity loss of $6061 \mathrm{Al}$ alloy can be reduced, so that 6061 $\mathrm{Al}$ alloy anodized with sulfuric acid has better strength.
\end{abstract}

Keywords: 6061 Al alloy;Intergranular corrosion; Oxidation treatment; Organizational structure; Mechanical property

\section{$\underline{\text { FULL TEXT }}$}

(C) 2021 The Authors. Published by ESG (www.electrochemsci.org). This article is an open access article distributed under the terms and conditions of the Creative Commons Attribution license (http://creativecommons.org/licenses/by/4.0/). 